\title{
An Examination of Driver Distraction as Recorded in NHTSA Databases
}

\section{Executive Summary}

Distraction from the primary task of driving could present a serious and potentially deadly danger. In $2008,5,870$ people lost their lives and an estimated 515,000 people were injured in police-reported crashes in which at least one form of driver distraction was reported on the crash report. While these numbers are significant, they may not state the true size of the problem, since the identification of distraction and its role in the crash by law enforcement can be very difficult.

The National Highway Traffic Safety Administration (NHTSA) has been researching driver distraction with respect to both behavioral and vehicle safety countermeasures in an effort to understand and mitigate crashes associated with driver distraction. In development of these countermeasures, the following data provide some perspective into the size of the problem of driver distraction:

Driver distraction was reported to have been involved in 16 percent of all fatal crashes in 2008 according to data from the Fatality Analysis Reporting System (FARS).

The age group with the greatest proportion of distracted drivers was the under-20 age group -16 percent of all under-20 drivers in fatal crashes were reported to have been distracted while driving.

An estimated 21 percent of injury crashes were reported to have involved distracted driving, according to data from the General Estimates System (GES).

Based on data from the National Motor Vehicle Crash Causation Survey (NMVCCS), a nationally representative survey, of the crashes in which the critical reason for the crash was attributed to the driver, approximately 18 percent involved distraction.

During the 100-Car Naturalistic Driving Study, driver involvement in secondary tasks contributed to over 22 percent of all crashes and near-crashes recorded during the study period.
There has been increased attention on the danger of distracted driving recently, specifically on the dangers of cell phone use and texting while driving. Other secondary task involvement includes eating, drinking, conversing with passengers, as well as interaction with in-vehicle technologies and portable electronic devices. Greater sophistication in these technologies may present greater physical and cognitive challenges for drivers than traditional information sources. Less obvious forms of cognitive distractions such as daydreaming or dealing with strong emotions also present potentially dangerous situations for drivers.

Measuring driver distraction in the field is difficult and potentially imprecise because of self-reporting and timing of data collection. Due to differences in methodology and definitions of distraction, each study or survey conducted may arrive at different results and conclusions with respect to the involvement of driver distraction during a crash. NHTSA's research paper Driver Distraction: A Review of the Current State-of-Knowledge discusses multiple means of measuring the effects of driver distraction including observational studies, crash-based studies, and experimental studies of driving performance (Ranney, 2008). Each type of study has its own set of advantages and disadvantages. This research note provides data from observations, surveys, and crash-based studies with varied methodologies and definitions of distraction, thus presenting several perspectives on the effects of driver distraction.

The purpose of this research note is to provide fatality, injury, on-scene crash investigation, and survey data associated with distracted driving and to summarize recent data from NHTSA and other DOT modes pertaining to distracted-driving crashes.

\section{Methodology and Limitations}

The beginning of this research note looks at the number of fatalities and people injured during crashes involving driver distraction over the previous five years (2004-2008). 
The data sources include NHTSA's Fatality Analysis Reporting System (FARS) and National Automotive Sampling System (NASS) General Estimates System (GES). FARS annually collects fatal crash data from 50 States, the District of Columbia, and Puerto Rico, and is a census of all fatal crashes that occur on the Nation's roadways. NASS GES contains data from a nationally representative sample of police-reported crashes of all severities, including those that result in death, injury, or property damage. Data presented from NASS GES are estimates and are used to describe crashes of all severities that occur on the Nation's roadways. The national estimates produced from GES data may differ from the true values because they are based on a probability sample of crashes-not a census of all crashes-and hence are subject to sampling errors.

NHTSA-sponsored research papers and studies (see references below) were reviewed to determine what activities constitute driver distraction:

The Role of Driver Inattention in Crashes: New Statistics From the 1995 Crashworthiness Data System (Wang et al., 1996)

An Overview of the 100-Car Naturalistic Study and Findings (Neale, 2005)

Driver Distraction: A Review of the Current State of Knowledge (Ranney, 2008)

Based on these documents, driver distraction in the context of this research note includes participation in secondary tasks and cognitive distraction. FARS and GES codes were reviewed to determine the appropriate search criteria in the databases that would incorporate distraction activities and behaviors identified in these NHTSA-sponsored research papers.

The databases include codes that accommodate participation in secondary tasks and cognitive distraction. FARS collects "Driver-Related Factors" that are coded in such a manner that can capture distractions such as the use of cell phones, navigation systems, and personal digital assistants (PDAs). This variable also captures careless and inattentive driving from cognitive distractions such as daydreaming. Appendix A provides the specific codes, definitions, and examples for "Driver-Related Factors" in the FARS database used in collection of fatal crash data involving distracted driving. This information is found in the annual FARS Coding and Validation Manual. GES has a code to include distraction but is more specific than the FARS database to the type of distraction after recognizing that distraction was already involved. The variable "Driver Distracted by" can include other occupants,

NHTSA's National Center for Statistics and Analysis vehicle systems, electronic devices, and eating or drinking among other secondary tasks. Appendix B shows specific codes that were used within GES to estimate the number of non-fatal (injury and property-damage-only) distracted-driving crashes and people injured in distracteddriving crashes.

There are inherent limitations to FARS and GES data with regard to distraction. The data for FARS and GES are based on police accident reports (PARs) and investigations which are conducted after the event has occurred. These codes that identify distraction involvement in FARS and GES do not assign cause of the crash, but are factors that are reported by law enforcement that may have played a role in the crash. Police accident reports vary across jurisdictions, thus creating potential inconsistencies in reporting. Many variables on the police crash report are concrete across the jurisdictions, but distraction is not one of those variables. Some police crash reports identify distraction as a distinct reporting field, while others do not have such a field and identification of distraction is based upon the narrative portion of the report. A review of the 2008 distracted-driving fatal crashes across States in FARS shows as few as 1 percent to as many as 56 percent of fatal crashes involved distraction. Similarly in GES, less than 1 percent of crashes were reported as involving distraction in one primary sampling unit and as many as 70 percent of crashes involved distraction in another primary sampling unit. The FARS and GES data discussed in this research note are only those crashes in which at least one form of driver distraction was reported by law enforcement thus presenting a potential for an undercount of crashes and fatalities.

There are negative implications associated with distracted driving-especially in conjunction with a crash. Survey research shows that self-reporting of negative behavior is lower than actual occurrence of that negative behavior. There is no reason to believe that self-reporting of distracted driving to a law enforcement officer would differ. The inference herein is that the reported driver distraction during crashes is lower than the actual occurrence. Additionally, if a driver fatality occurs in the crash, law enforcement must rely on the crash investigation in order to report on whether driver distraction was involved. Law enforcement may not have information to indicate distraction.

Further discussion in the research note includes data from the National Motor Vehicle Crash Causation Survey (NMVCCS). Researchers were permitted on the scene of the crash and conducted analysis of the crash scene to thoroughly examine factors associated with the crash. Interviews were conducted when appropriate and information regarding distraction could be ascertained in this manner. The problems with self-reporting negative behav- 
ior in this survey would be similar to FARS and GES data. Appendix $C$ contains information on the data collection method for this survey and full details can be found in the NMVCCS Report to Congress (NHTSA, 2008).

The 100-Car Naturalistic Driving Study conclusions provide perspective from an observational study. The data collection process utilized in this study provides great detail about driver activity and behavior at the time of the crash as well as information about the driving maneuvers preceding and during the crash. The information regarding the crash is retrieved through video and sensors among other advanced technologies and is therefore not biased by self-reporting. The limitations in these data arise from the purposive, and relatively small, sample-designed to maximize the potential to record a crash or near crash. This prevents the results of the study from being projected to all types of drivers, all vehicles, and all environments.

Despite the differences in the studies, each piece of data provides insight into the problem of distracted driving on the Nation's roadways.

\section{Presentation of Data}

\section{Fatalities in Crashes With Driver Distraction}

In 2008, there were a total of 34,017 fatal crashes in the United States involving 50,186 drivers. In those crashes, 37,261 individuals were killed. Distraction was reported for 11 percent $(5,501)$ of the drivers involved in fatal crashes. In these crashes reported to have involved distraction, 5,870 fatalities (16\% of the overall fatalities) occurred. Table 1 provides information about fatal crashes with reported distraction from 2004 through 2008.

The proportion of fatalities reportedly associated with driver distraction increased from 12 percent in 2004 to 16 percent in 2008. During that time, fatal crashes with reported driver distraction also increased from 11 percent to 16 percent.
As reported for 2008, 5,331 fatal crashes occurred that involved distraction which includes single-vehicle crashes and multi-vehicle crashes. For single-vehicle crashes, the driver was reported as distracted and thus the crash was reported as a distracted-driving crash. However, in multivehicle crashes, the crash was reported as a distracteddriving crash if at least one driver was reported as distracted. In some of these multi-vehicle crashes, multiple drivers were reported as distracted. In 2008, 5,501 drivers were reported as distracted in the 5,331 fatal crashes involving distraction. The portion of drivers reportedly distracted at the time of the fatal crash increased from 8 percent in 2004 to 11 percent in 2008.

Table 2 describes 2008 fatal crash data by age of drivers with reported distracted-driving behavior and the types of vehicles driven. The age group with the greatest proportion of distracted drivers was the under-20 age group-16 percent of all under-20 drivers in fatal crashes were reported to have been distracted while driving. The age group with the next greatest proportion was 20- to 29-year-old drivers-12 percent of all 20- to 29-year-old drivers in fatal crashes were distracted. Light-truck drivers and motorcyclists had the greatest percentage of total drivers reported as distracted at the time of the fatal crash (12\% each). Large-truck drivers had the smallest percentage of total drivers involved in fatal crashes that were reported as distraction-related. Table 2 shows fatal crashes by the age of the driver who was reportedly distracted and the vehicles with the distracted drivers.

\section{People Injured in Crashes Involving Driver Distraction}

In 2008, an estimated 2,346,000 people were injured in motor vehicle traffic crashes. The number of people injured during a crash with reported distraction in 2008 was estimated at 515,000 ( $22 \%$ of all the injured people). Table 3 provides information about people injured in crashes with reported distraction from 2004 through 2008.

The estimated number of people injured in crashes involving distracted driving fell by 28 percent from an estimated

Table 1

Fatal Crashes, Drivers, and Fatalities in Crashes Involving Driver Distraction by Year

\begin{tabular}{c|c|c|c|c|c|c}
\hline \multirow{2}{*}{ Year } & \multicolumn{3}{|c|}{ Overall } & \multicolumn{3}{c}{ Distraction } \\
\cline { 2 - 6 } & Crashes & Drivers & Fatalities & Crashes & Drivers & Fatalities \\
\hline 2004 & 38,444 & 58,395 & 42,836 & $4,409(11 \%)$ & $4,672(8 \%)$ & $4,978(12 \%)$ \\
\hline 2005 & 39,252 & 59,220 & 43,510 & $4,117(10 \%)$ & $4,309(7 \%)$ & $4,572(11 \%)$ \\
\hline 2006 & 38,648 & 57,846 & 42,708 & $5,323(14 \%)$ & $5,536(10 \%)$ & $5,917(14 \%)$ \\
\hline 2007 & 37,435 & 56,019 & 41,259 & $5,398(14 \%)$ & $5,623(10 \%)$ & $5,988(15 \%)$ \\
\hline 2008 & 34,017 & 50,186 & 37,261 & $5,331(16 \%)$ & $5,501(11 \%)$ & $5,870(16 \%)$ \\
\hline
\end{tabular}

Source: NCSA, FARS 2004-2007 (Final), 2008 (ARF) 
713,000 in 2004 to 515,000 in 2008. The estimated overall number of people injured only fell 16 percent during the same time period.

Table 2

Drivers Involved in Fatal Crashes by Age and Vehicle Type, 2008

\begin{tabular}{l|c|c}
\hline & Total Drivers & Distracted Drivers \\
\hline Total & $\mathbf{5 0 , 1 8 6}$ & $\mathbf{5 , 5 0 1 ( 1 1 \% )}$ \\
\hline \multicolumn{3}{|c|}{ Drivers by Age Group } \\
\hline Under 20 & 4,535 & $707(16 \%)$ \\
\hline $20-29$ & 12,132 & $1,449(12 \%)$ \\
\hline $30-39$ & 8,684 & $886(10 \%)$ \\
\hline $40-49$ & 8,760 & $915(10 \%)$ \\
\hline $50-59$ & 7,161 & $665(9 \%)$ \\
\hline $60-69$ & 4,089 & $405(10 \%)$ \\
\hline 70 and Over & 3,977 & $436(11 \%)$ \\
\hline \multicolumn{3}{|c|}{ Drivers by Vehicle Type } \\
\hline Passenger Car & 20,284 & $2,124(10 \%)$ \\
\hline Light Truck & 18,989 & $2,310(12 \%)$ \\
\hline Large Truck & 4,017 & $324(8 \%)$ \\
\hline Motorcycle & 5,383 & $621(12 \%)$ \\
\hline Bus & 247 & $21(9 \%)$ \\
\hline
\end{tabular}

Source: NCSA, FARS 2008 (ARF)

Table 3

People Injured in Crashes and People Injured in Crashes Involving Distraction

\begin{tabular}{c|c|c|c}
\hline \multirow{2}{*}{ Year } & \multirow{2}{*}{ Overall } & \multicolumn{2}{|c}{ Distraction } \\
\cline { 3 - 4 } & & Estimate & $\begin{array}{c}\text { Percentage of } \\
\text { Total }\end{array}$ \\
\hline 2004 & $2,788,000$ & 713,000 & $26 \%$ \\
\hline 2005 & $2,699,000$ & 674,000 & $25 \%$ \\
\hline 2006 & $2,575,000$ & 565,000 & $22 \%$ \\
\hline 2007 & $2,491,000$ & 506,000 & $20 \%$ \\
\hline 2008 & $2,346,000$ & 515,000 & $22 \%$ \\
\hline
\end{tabular}

Source: NCSA, GES 2004-2008

\section{Crashes of All Severity With Distraction}

Table 4 provides information for all police-reported crashes from 2004 through 2008 including fatal crashes, injury crashes, property-damage-only crashes, and the total number of crashes for the year.

Figure 1 provides a graphical representation of the percentage of distracted-driving crashes for a particular severity from 2004 through 2008. This graph illustrates any fluctuation during the five-year period. From 2004 to 2008 , the percentage of fatal crashes involving distraction increased, while the percentage of injury crashes and property-damage-only crashes involving driver distraction decreased.
Table 4

Motor Vehicle Traffic Crashes and Crashes

Involving Driver Distraction by Year

\begin{tabular}{c|l|r|r}
\hline \multicolumn{2}{c|}{$\begin{array}{c}\text { Crash Year } \\
\text { By Crash Severity }\end{array}$} & $\begin{array}{c}\text { Overall } \\
\text { Crashes }\end{array}$ & $\begin{array}{c}\text { Crashes Involving } \\
\text { Distraction }\end{array}$ \\
\hline \multirow{4}{*}{2004} & Fatal Crash & 38,444 & $4,409(11 \%)$ \\
\cline { 2 - 4 } & Injury Crash & $1,862,000$ & $478,000(26 \%)$ \\
\cline { 2 - 4 } & PD0 Crash & $4,281,000$ & $998,000(23 \%)$ \\
\cline { 2 - 4 } & Total & $6,181,000$ & $1,481,000(24 \%)$ \\
\hline \multirow{4}{*}{2005} & Fatal Crash & 39,252 & $4,117(10 \%)$ \\
\cline { 2 - 4 } & Injury Crash & $1,816,000$ & $448,000(25 \%)$ \\
\cline { 2 - 4 } & PDO Crash & $4,304,000$ & $1,021,000(24 \%)$ \\
\cline { 2 - 4 } & Total & $6,159,000$ & $1,472,000(24 \%)$ \\
\hline \multirow{4}{*}{2006} & Fatal Crash & 38,648 & $5,323(14 \%)$ \\
\cline { 2 - 4 } & Injury Crash & $1,746,000$ & $381,000(22 \%)$ \\
\cline { 2 - 4 } & PD0 Crash & $4,189,000$ & $769,000(18 \%)$ \\
\cline { 2 - 4 } & Total & $5,973,000$ & $1,155,000(19 \%)$ \\
\hline \multirow{3}{*}{2007} & Fatal Crash & 37,435 & $5,398(14 \%)$ \\
\cline { 2 - 4 } & Injury Crash & $1,711,000$ & $349,000(20 \%)$ \\
\cline { 2 - 4 } & PDO Crash & $4,275,000$ & $787,000(18 \%)$ \\
\cline { 2 - 4 } & Total & $6,024,000$ & $1,142,000(19 \%)$ \\
\hline \multirow{3}{*}{2008} & Fatal Crash & 34,017 & $5,331(16 \%)$ \\
\cline { 2 - 4 } & Injury Crash & $1,630,000$ & $350,000(21 \%)$ \\
\cline { 2 - 4 } & PD0 Crash & $4,146,000$ & $745,000(18 \%)$ \\
\cline { 2 - 4 } & Total & $5,811,000$ & $1,100,000(19 \%)$ \\
\hline
\end{tabular}

Source: NCSA, FARS 2004-2007 (Final), 2008 (ARF), GES 2004-2008; PDOProperty Damage Only.

Figure 1

Crashes Involving Driver Distraction by Crash Severity

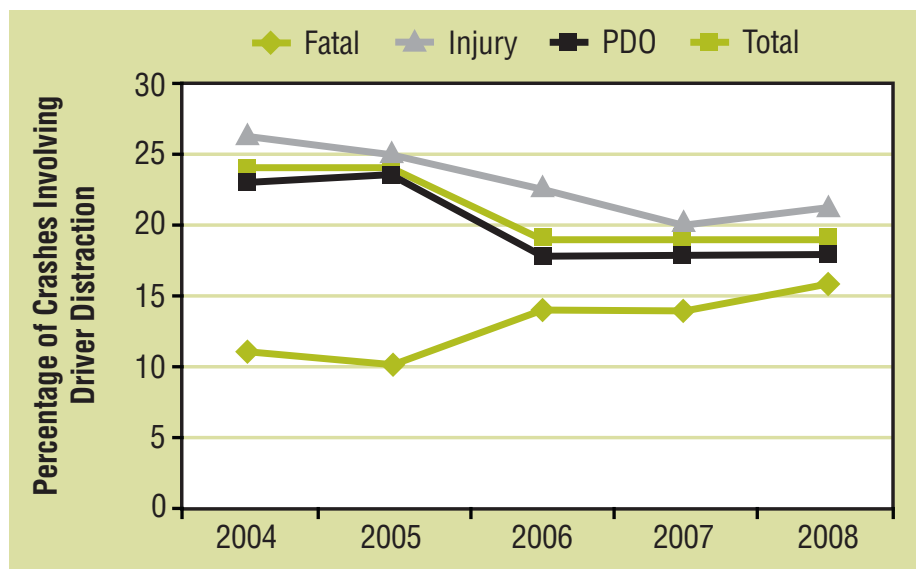

Source: NCSA, FARS 2004-2007 (Final), 2008 (ARF), GES 2004-2008; PD0-Property Damage Only

\section{Recent NHTSA-Sponsored Studies Involving Distracted Driving}

NHTSA has focused a great deal of attention on driver distraction to minimize distracted-driving behavior, develop countermeasures to prevent distracted-driving crashes, and mitigate injuries and fatalities that occur during a distracted-driving crash. The National Motor Vehicle Crash Causation Survey (NMVCCS) and the 100-Car Naturalistic Driving Study provide data about distracted- 
driving crashes collected in different methods than FARS and GES, thus presenting varied measures of how frequently distraction is involved in motor vehicle crashes.

NHTSA has also collected data on the use of electronic devices-distractions of great interest recently. Electronicdevice-use and cell-phone-use data from two surveys, the National Occupant Protection Use Survey (NOPUS) and the Motor Vehicle Occupant Safety Survey (MVOSS), are included as well.

\section{National Motor Vehicle Crash Causation Survey}

NHTSA recently conducted a nationwide survey of crashes involving light passenger vehicles with a focus on factors related to pre-crash events (NHTSA, July 2008). The NMVCCS investigated a total of 6,950 crashes during the three-year period from January 2005 to December 2007. The report uses a nationally representative sample of 5,471 crashes that were investigated during a two-anda-half-year period from July 3, 2005, to December 31, 2007. Based on the sampling method of the survey, findings are representative of the Nation as a whole. The survey was unique in that researchers were granted permission from law enforcement and emergency responders to be on the scene of the crash. Further discussion on the methodology and definitions of distraction in NMVCCS can be found in Appendix C.

Survey researchers were able to assess the critical event that preceded the crash, the reason for this event, and any other associated factors that might have played a role. Examples of the critical event preceding the crash include running off the edge of the road, failure to stay in the proper lane, or loss of control of the vehicle. Researchers assessed the reason underlying this critical event and attributed that reason to either the driver, the condition of the vehicle, failure of the vehicle systems, adverse environmental conditions, or roadway design. Each of these areas was further broken down to determine more specific critical reasons. For the driver, critical reasons included facets of driver distraction and therefore NMVCCS was able to quantify driver distraction involvement in crashes. The percentages included in this discussion are based on statistical weighting of the 5,471 crashes.

In cases where the researchers attributed the critical reason of the pre-crash event to the driver, distraction was identified. The definitions for types of distraction in NMVCCS-inattention, ${ }^{1}$ internal distraction, and external

\footnotetext{
${ }^{1}$ Note that inattention in some research documents refers to distraction and fatigue. For NMVCCS, inattention refers solely to inattentive behavior-focusing of attention on concerns other than driving.
}

distraction-coincide with previous research and thus also coincide with the criteria used to capture distraction in FARS and GES. Inattention was cited as the critical reason in 3 percent of the crashes, internal distraction was cited in 11 percent of the crashes, and external distraction was cited in 4 percent of the crashes. Overall, an estimated 18 percent of the crashes were reported to have involved driver distraction.

In addition to reporting distraction as the critical reason for the pre-crash event, NMVCCS also reports crash-associated factors. This is a factor likely to add to the probability of a crash occurrence and can be attributed to the driver, vehicle, roadway, or environment-the same categories as the critical reason classification. Eighteen percent of drivers were engaged in at least one interior non-driving activity (e.g., looking at other occupants, dialing or hanging up a phone, or conversing with a passenger). These interior non-driving activities are similar in definition to secondary task distractions noted in previous research. Drivers ages 16 to 25 had the highest percentage of being engaged in at least one interior non-driving activity.

\section{0-Car Naturalistic Driving Study}

The 100-Car Naturalistic Driving Study was an observational study-via instrumented vehicles-to provide details on driver performance, behavior, environment, and other factors associated with critical incidents, nearcrashes, and crashes for 100 drivers over a one-year period (Ranney, 2008). The study was conducted as an exploratory study to determine the feasibility of a larger-scale study that would be more representative of the Nation's driving behavior. Despite the small-scale of the 100-Car study, extensive information was obtained on 241 primary and secondary drivers over a 12- to 13-month period. The data covered approximately 2 million vehicle miles driven and 43,000 hours of driving. Further details on the methodology of the 100-car study and activities included as secondary tasks in the study can be found in Appendix D.

As stated in An Overview of the 100-Car Naturalistic Study and Findings, "the goal of this study was to maximize the potential to record crash or near crash events through the selection of subjects with higher than average crash or near crash risk exposure." In order to achieve this goal, the 100-car study selected a larger sample of drivers who were under the age of 25 and who drove more than average. Additionally, the subjects were selected from the Northern Virginia/Washington, DC, metropolitan area which offers primarily urban and suburban driving conditions, often in moderate to heavy traffic. This type of purposive sample well-served the intentions of the study; however, it placed limitations on the application of the 
findings. The findings of the 100-car study cannot be generalized to represent the behavior of the Nation's population or the potential causal factors for the crashes that occur across the Nation's roadways.

During the 100-car study, complete information was collected on 69 crashes, 761 near-crashes, and 8,295 incidents. The encompassing term inattention was classified during this study as 1) secondary task involvement, 2) fatigue, 3) driving-related inattention to the forward roadway, and 4) non-specific eye glance away from the forward roadway. Secondary task involvement is defined for the study as driver behavior that diverts the driver's attention away from the driving task; may include listening to cell phone, eating, talking to a passenger, etc. Thus, secondary task involvement in the 100-car study closely corresponds to the behaviors of distraction. Results of the 100-car study indicate that secondary task distraction contributed to over 22 percent of all the crashes and near-crashes recorded during the study period (NHTSA, 2006).

\section{National Occupant Protection Use Survey}

NHTSA's annual survey of occupant protection also collects data on electronic device use. NOPUS provides the only probability-based observed data on driver electronic device use in the United States (NHTSA, June 2008). Based on the sampling method of the survey, findings are representative of the Nation as a whole. In 2007, hand-held electronic device use by drivers was up to 6 percent, an increase from the previous year. This rate translates into $1,005,000$ vehicles on the road at any given daylight (7 a.m. to 6 p.m.) moment being driven by someone using a handheld electronic device. It also translates into an estimated 11 percent of vehicles in the typical daylight moment whose driver is using some type of electronic device, either hand-held or hands-free.

\section{Motor Vehicle Occupant Safety Survey}

The 2007 MVOSS is a periodic national telephone survey on occupant protection issues. Volume 4, Crash Injury and Emergency Medical Services Report, includes discussion of questions pertaining to wireless phone use in the vehicle (Boyle \& Lampkin, 2008). According to the report, 81 percent of people age 16 and older have a wireless phone in the vehicle when they drive. This rate decreases as age increases-87 percent of 16- to 54-year olds, 74 percent of 55- to 64-year-olds, and 63 percent of individuals age 65 and older. Of those individuals who have a wireless phone in the vehicle, 85 percent said they keep the phone on during all or most of their trips. Sixty-four percent always or usually answer incoming phone calls.
Of the drivers who usually carry a wireless phone, 16 percent said they talk while driving during most or all of their trips and 17 percent said they talk on their wireless phone during half of their trips. On the other hand, 22 percent of individuals reported never talking on their phone while in the vehicle.

With respect to making phone calls while in the vehicle, 32 percent of those who at least occasionally talk on the phone while driving place the phone call while driving the vehicle. An additional 37 percent wait until a temporary stop, and 19 percent pull over to a stop to place the call. Ten percent stated they never make a phone call while in the car.

\section{Research and Innovative Technology Administration (RITA) Research}

\section{Analysis of Crashes Involving Driver Distraction Using the 2003 GES Database}

In 2005, the Volpe National Transportation Systems Center released a report for the Research and Innovative Technology Administration regarding driver distraction. The report examined driver distraction as a contributing factor in all motor vehicle crashes and major crash types based on the 2003 GES crash database (Foderaro \& Najm, 2005). Among other objectives, the analysis sought to quantify the involvement of distraction in terms of its frequency of occurrence.

Based on 2003 GES statistics, distraction was cited in about 14 percent of the $6,318,000$ police-reported crashes. By excluding unknowns, distraction accounted for 24 percent of all crashes through the proportional redistribution of crashes. Appendix $G$ discusses criteria used for the search of distraction data within GES. 


\section{References}

Boyle, J. M., and Lampkin, C. (2008). 2007 Motor Vehicle Occupant Safety Survey Volume 4: Crash Injury and Emergency Medical Services Report. DOT HS 810977.

Foderaro, F., and Najm, W. (2005). Analysis of Crashes Involving Driver Distraction Using the 2003 GES Database.

National Highway Traffic Safety Administration. (2006, April). The Impact of Driver Inattention on Near Crash/Crash Risk: An Analysis Using the 100-Car Naturalistic Driving Study Data. DOT HS 810594.

National Highway Traffic Safety Administration. (2008, July). National Motor Vehicle Crash Causation Survey: Report to Congress. DOT HS 811059.

National Highway Traffic Safety Administration. (2008, June). Traffic Safety Facts Research Note: Driver Electronic Device Use in 2007. DOT HS 810963.

Neale, V. L. (2005). An Overview of the 100-Car Naturalistic Study and Findings. National Highway Traffic Safety Administration and Virginia Tech Transportation Institute. www.nhtsa.dot.gov/staticfiles/DOT/NHTSA/NRD/ Multimedia/PDFs/Crash\%20Avoidance/Driver\%20 Distraction/100Car_ESV05summary.pdf

Ranney, T. A. (2008). Driver Distraction: A Review of the Current State-of-Knowledge. National Highway Traffic Safety Administration. DOT HS 810787.

Wang, J-S. (1996). The Role of Driver Inattention in Crashes: New Statistics from the 1995 Crashworthiness Data System. www-nrd.nhtsa.dot.gov/departments/Human $\% 20$ Factors/driver-distraction/PDF/Wang.PDF

Information on Distraction is presented by NHTSA's Office of Vehicle Safety Research on the Internet at: www. nhtsa.dot.gov/portal/site/nhtsa/template.MAXIMIZE/ menuitem.8f0a414414e99092b477cb30343c44cc/?javax. portlet.tpst $=4670 \mathrm{~b} 93 \mathrm{a} 0 \mathrm{~b} 088 \mathrm{a} 006 \mathrm{bc1d6b760008a0c \_ ws}$ MX\&javax.portlet.prp_4670b93a0b088a006bc1d6b760008a 0c_viewID=detail_view\&itemID=97b964d168516110VgnV CM1000002fd17898RCRD\&overrideViewName=Article

Information on Drowsy and Distracted Driving is presented by NHTSA's Office of Traffic Injury Control on the Internet at: www.nhtsa.dot.gov/portal/site/nhtsa/menuit em.54757ba83ef160af9a7ccf10dba046a0/

\section{Authors}

This research note was written by Debra Ascone and Tonja Lindsey in the Data Reporting and Information Division, National Center for Statistics and Analysis, NHTSA, and by Cherian Varghese, a contractor employed by URC Enterprises, working with the Data Reporting and Information Division, National Center for Statistics and Analysis, NHTSA. 


\section{Appendix A}

\section{FARS Coding for Driver Distraction}

\begin{tabular}{c|l|l}
\hline FARS Variable & \multicolumn{1}{|c}{ Related Factor } & \multicolumn{1}{|c}{ Examples in Manual } \\
\hline Driver-Related Factor & Emotional (e.g., Depression, Angry, Disturbed) & Fighting, disagreements, depressed, and emotionally upset. \\
\cline { 2 - 3 } & $\begin{array}{l}\text { Operating the Vehicle in Careless or Inattentive } \\
\text { Manner }\end{array}$ & $\begin{array}{l}\text { Includes use of car/cell phones, text messaging, fax, GPS/Head-up display } \\
\text { systems, DVD player, etc.; Driver distracted by children; Driver lighting } \\
\text { cigarette; Operating or adjusting radio and other accessories; Reading, } \\
\text { talking, daydreaming, eating, looking for an address, crash in next lane, } \\
\text { automated highway sign, approaching emergency vehicle, using electric } \\
\text { razor, applying cosmetics, painting nails, etc. }\end{array}$ \\
\cline { 3 - 3 } & Cellular Telephone Present in Vehicle & Includes hand-held and hands-free cellular telephones. \\
\cline { 2 - 3 } & Cellular Telephone in Use in Vehicle & Laptop/notebook computers; PDAs; Fax machines; Printers. \\
\cline { 2 - 3 } & Computer/Fax Machines/Printers & \\
\cline { 2 - 3 } & Onboard Navigation System & \\
\cline { 2 - 3 } & Two-Way Radio & \\
\cline { 2 - 3 } & Head-up Display & \\
\hline
\end{tabular}

Beginning in 2010, FARS and GES variables and codes will be the same. This consolidation will create a slight change in the criteria used for determining the number of crashes involving driver distraction.

\section{Appendix B}

\section{GES Coding for Driver Distraction}

\begin{tabular}{|c|c|c|}
\hline GES Variable & Related Factor & Definition in Manual (abbreviated) \\
\hline \multirow[t]{16}{*}{ Driver Distracted by } & Looked but did not see & $\begin{array}{l}\text { Paying attention to driving but does not see the relevant vehicle, object, } \\
\text { etc. (blind spot, intersections) }\end{array}$ \\
\hline & By other occupant & $\begin{array}{l}\text { Distracted by occupant in driver's vehicle; includes conversing with or } \\
\text { looking at other occupant. }\end{array}$ \\
\hline & By moving object in vehicle & $\begin{array}{l}\text { Distracted by moving object in driver's vehicle; includes dropped object, } \\
\text { moving pet, insect, cargo. }\end{array}$ \\
\hline & While talking or listening to cellular phone & Talking or listening on cellular phone. \\
\hline & While dialing cellular phone & Dialing or text messaging on cell phone or any wireless email device. \\
\hline & Other Cellular Phone Related (2007+) & $\begin{array}{l}\text { Used when the Police Report indicates the driver is distracted from the } \\
\text { driving task due to cellular phone involvement, but none of the specified } \\
\text { codes are applicable (e.g., reaching for cellular phone, etc.). This code is } \\
\text { also applied when specific details regarding cellular phone distraction / } \\
\text { usage are not provided. }\end{array}$ \\
\hline & While adjusting climate controls & Adjusting air conditioner or heating. \\
\hline & While adjusting radio, cassette, CD & Adjusting radio, cassette, or CD in vehicle. \\
\hline & While using other device/controls integral to vehicle & $\begin{array}{l}\text { Adjusting windows, door locks, rear view manual, seat, steering wheel, } \\
\text { adjusting seat belt, etc. }\end{array}$ \\
\hline & $\begin{array}{l}\text { While using or reaching for device/object brought } \\
\text { into vehicle }\end{array}$ & $\begin{array}{l}\text { Radar detector, CDs, razors, portable CD player, headphones, cigarette } \\
\text { lighter, etc. }\end{array}$ \\
\hline & Distracted by outside person, object, or event & $\begin{array}{l}\text { Animals on roadside or previous crash. Do not use when driver has } \\
\text { recognized object/event and driver taken some evasive action. }\end{array}$ \\
\hline & Eating or drinking & Eating or drinking or activity related to these actions. \\
\hline & Smoking related & Smoking or involved in activity related to smoking. \\
\hline & Distraction/inattention, details unknown & $\begin{array}{l}\text { Distraction and/or inattention are noted on the PAR but the specifics are } \\
\text { unknown. }\end{array}$ \\
\hline & Inattentive or lost in thought & Driver is thinking about items other than the driving task (daydreaming). \\
\hline & Other distraction & $\begin{array}{l}\text { Details regarding this driver's distraction are known but none of the } \\
\text { specified codes are applicable. }\end{array}$ \\
\hline
\end{tabular}

Beginning in 2010, FARS and GES variables and codes will be the same. This consolidation will create a slight change in the criteria used for determining the number of crashes involving driver distraction. 


\section{Appendix C}

\section{National Motor Vehicle Crash Causation Survey}

NMVCCS investigated a total of 6,950 crashes during the 3-year period from January 2005 to December 2007. However, this report uses a nationally representative sample of 5,471 crashes that were investigated during a twoand-a-half-year period from July 3, 2005, to December 31, 2007. The remaining 1,479 crashes were investigated but were not used in this report because 1) these crashes were investigated during the transition period from January 1 , 2005, to July 2, 2005, when the data collection effort was being phased in, or 2) these crashes were investigated after the phase-in period, but ultimately determined not to meet the requisite sample selection criteria. However, the data from the 1,479 crashes is still suitable for clinical, case-by-case evaluations and will be part of the file that will be released for public use. Each investigated crash involved at least one light passenger vehicle that was towed due to damage. Data was collected on at least 600 data elements to capture information related to the drivers, vehicles, roadways, and environment. In addition, the NMVCCS database includes crash narratives, photographs, schematic diagrams, vehicle information, and event data recorder (EDR) data, when available. This additional information will be vital to researchers seeking to perform in-depth clinical reviews of crashes.

In the NMVCCS Coding Manual, page 308 describes coding for the pre-crash assessment. The following codes for the variable precrash.critical_reason were those included as distraction for the critical reason for the critical precrash event:

Inattention (i.e., daydreaming)—Used when the driver fails to recognize a situation that demands a response because his/her attention has wandered from the driving task for some non-compelling reason. In this circumstance, the driver is typically focusing on internal thoughts (i.e., daydreaming, problem-solving, worrying about family problem, etc.) and not focusing attention on the driving task.

Internal distraction-Reserved for crashes in which the driver fails to recognize a situation requiring a response because his/her attention is directed to some event, object, person, or activity inside the vehicle. Relevant examples include tuning the radio, adjusting the heat/ cooling system, engaging in a conversation with a passenger, using a cell phone, retrieving fallen objects, reading books/magazines/maps/invoices, etc.

External distraction-Reserved for crashes in which the driver fails to recognize a situation requiring a response because his/her attention is directed to some event, object, person, or activity outside the vehicle. Relevant examples include searching for a street address, construction activity, looking at a building or scenery, looking at a sign, looking at a previous crash site, etc. Distractions are distinguished from inattention in that distractions induce the driver to focus attention on the distraction. This category takes precedence over the next category (inadequate surveillance). If, for example, a driver fails to look because he/she is distracted, code external or internal distraction as appropriate.

The NMVCCS Coding Manual, page 404 describes coding for the pre-crash assessment, specifically identifying nondriving activities. The following codes were those included for interior non-driving activities for the variable driveractivity.other_driver_activity for the crash-associated factors:

Looking at movement/actions of other occupantsUsed when the driver is distracted by other occupants in the vehicle. The specific intent is to identify instances when the driver is distracted by movements or actions initiated by these occupants. Distraction as a result of conversation is classified in the preceding variable.

Dialing/hanging-up phone-Used when the driver is distracted as a result of either dialing or hanging-up a phone during the pre-crash phase. This element value is also used when the driver is adjusting phone controls or is attempting to retrieve voicemail messages.

Adjusting radio/CD player-Used when the driver is distracted as a result of attempting to adjust sound system controls.

Adjusting other vehicle controls-Used when the driver is distracted as a result of attempting to adjust the heat, vent, or air conditioning controls. This category also includes attempted adjustments to other OEM and aftermarket controls. Electronic file data entries should be annotated to indicate the system involved and the attempted adjustment.

Retrieving object from floor and/or seat-Used when the driver is attempting to retrieve an object from either indicated location while driving. The objects in this category include everything with the exception of items related to smoking or eating which are addressed in selection of those individual attributes.

Retrieving object from other location-Used when the driver is attempting to retrieve an object from a location other than the floor or seat. Objects in this category include everything with the exception of items related 
to smoking or eating which are addressed in selection of those individual attributes.

Eating or drinking

Smoking

Reading map/directions/newspaper, etc.

Focused on other internal object (specify)-Use this attribute when the driver is not attending to the driving task due to focus on any object in the interior of the vehicle not related to other specific attributes for this variable.

Text messaging-Any short electronically transmitted message. Typically sent to a handheld device such as a pager, PDA, or cell phone.

\section{Appendix D}

\section{0-Car Naturalistic Driving Study}

The 100-Car Naturalistic Driving Study was an observational study conducted from January 2003 to July 2004 to provide detail concerning driver performance, behavior, environment, driving context, and other factors that were associated with critical incidents, near-crashes, and crashes for 100 cars. Information about the instrumentation of the vehicle, the subjects selected for the study, and the vehicles used in the study are discussed below. Full details about the methodology and data collection in this study can be found in multiple reports including $A n$ Overview of the 100-Car Naturalistic Study and Findings.

\section{Instrumentation}

The 100-car instrumentation package was engineered by VTTI to be rugged, durable, expandable, and unobtrusive. The system consisted of a Pentium-based computer that received and stored data from a network of sensors distributed around the vehicle. Data storage was achieved via the system's hard drive, which was large enough to store data for several weeks of driving before requiring data downloading. A video subsystem was also included in the vehicle to provide a continuous window into the happenings in and around the vehicle. This subsystem included five camera views monitoring the driver's face and driver's side of the vehicle, the forward view, the rear view, the passenger's side of the vehicle, and an over-the shoulder view for the driver's hands and surrounding areas.

\section{Subjects}

One-hundred drivers who commuted into or out of the Northern Virginia/Washington, DC, metropolitan area were initially recruited as primary for this study. As some drivers had to be replaced for various reasons, 109 primary drivers were included in the study. As family members and friends would occasionally drive the instrumented vehicles, data were collected on 132 additional drivers. To maximize the potential to record crash and near-crash events through the selection of subjects with higher-thanaverage crash- or near-crash risk exposure, exposure was manipulated through the selection of a larger sample of drivers under the age of 25 , and by the selection of a sample that drove more than the average number of miles. One issue of note is that the data were collected in only the metropolitan DC area-with primarily urban and suburban driving conditions, often in moderate to heavy traffic.

\section{Vehicles}

Six different vehicle models were selected based upon their prevalence in the Northern Virginia area. These included five sedan models and one SUV model. The model years were limited to those with common body types and accessible vehicles.

\section{Activities Included as Secondary Tasks}

\begin{tabular}{|c|c|c|}
\hline $\begin{array}{c}\text { Simple Secondary } \\
\text { Tasks }\end{array}$ & $\begin{array}{c}\text { Moderate Secondary } \\
\text { Tasks }\end{array}$ & $\begin{array}{c}\text { Complex Secondary } \\
\text { Tasks }\end{array}$ \\
\hline 1. Adjusting radio & $\begin{array}{l}\text { 1. Talking/listening to } \\
\text { hand-held device }\end{array}$ & $\begin{array}{l}\text { 1. Dialing a hand-held } \\
\text { device }\end{array}$ \\
\hline $\begin{array}{l}\text { 2. Adjusting other } \\
\text { devices integral to } \\
\text { the vehicle }\end{array}$ & $\begin{array}{l}\text { 2. Hand-held device- } \\
\text { other }\end{array}$ & $\begin{array}{l}\text { 2. Locating/reaching/ } \\
\text { answering hand- } \\
\text { held device }\end{array}$ \\
\hline $\begin{array}{l}\text { 3. Talking to passenger } \\
\text { in adjacent seat }\end{array}$ & $\begin{array}{l}\text { 3. Inserting/retrieving } \\
\text { CD }\end{array}$ & 3. Operating a PDA \\
\hline $\begin{array}{l}\text { 4. Talking/Singing: No } \\
\text { passenger present }\end{array}$ & $\begin{array}{l}\text { 4. Inserting/retrieving } \\
\text { cassette }\end{array}$ & 4. Viewing a PDA \\
\hline 5. Drinking & $\begin{array}{l}\text { 5. Reaching for object } \\
\text { (not hand-held device) }\end{array}$ & 5. Reading \\
\hline 6. Smoking & 6. Combing or fixing hair & $\begin{array}{l}\text { 6. Animal/object in } \\
\text { vehicle }\end{array}$ \\
\hline 7. Lost in thought & $\begin{array}{l}\text { 7. Other personal } \\
\text { hygiene }\end{array}$ & $\begin{array}{l}\text { 7. Reaching for a } \\
\text { moving object }\end{array}$ \\
\hline \multirow[t]{2}{*}{ 8. Other } & 8. Eating & 8. Insect in vehicle \\
\hline & $\begin{array}{l}\text { 9. Looking at external } \\
\text { object }\end{array}$ & 9. Applying makeup \\
\hline
\end{tabular}




\section{Appendix E}

\section{National Occupant Protection Use Survey}

\section{Survey Methodology}

NOPUS is the only probability-based observational survey of driver electronic device use in the United States. The survey observes usage as it actually occurs at a random selection of roadway sites, and so provides the best tracking of the extent to which people in this country are using cell phones and other electronic devices while driving.

Data is collected between the hours of 7 a.m. and 6 p.m. Only stopped vehicles are observed to permit time to collect the variety of information required by the survey. Observers do not interview occupants, so that the NOPUS can capture the untainted behavior of occupants. The 2007 NOPUS data was collected between June 4 and June 25, while the 2006 data was collected between June 5 and June 26.

\section{Definitions}

Drivers were counted as "holding phones to their ears" if they were holding to their ears what appeared to the observer to be a phone. This would include such behaviors as drivers engaged in conversation, listening to messages, or conducting voice-activated dialing while holding a phone to their ears. Note that PDAs such as Blackberrys would count as phones.

Drivers were counted as "speaking with visible headsets on" if they appeared to be speaking and wearing a headset with a microphone. This would include such behaviors as talking in conversation or conducting voice-activated dialing via a wireless earpiece on the driver's right ear or via an earbud connected by wire to a cell phone.

Drivers were counted as "visibly manipulating hand-held devices" if they appeared to be manipulating some type of electronic device, whether a cell phone, PDA, video game, or other device. This would include such behaviors as manual dialing; text messaging; using a Web-capable cell phone or a PDA (such as a Blackberry) to view travel directions, check e-mails or calendar appointments, or surf the Internet; playing hand-held games; and holding phones in front of their faces to converse or check messages via speakerphone or use voice-activated dialing.

Further details about the methodology of NOPUS and the definitions included in electronic device use can be found in the Traffic Safety Fact Sheet (NHTSA, 2008).

\section{Appendix F}

\section{Motor Vehicle Occupant Safety Survey}

The 2007 MVOSS was the sixth in a series of periodic national telephone surveys on occupant protection issues conducted for NHTSA. Data collection was conducted by Schulman, Ronca, \& Bucuvalas, Inc., a national survey research organization. The survey used two questionnaires, each administered to a randomly selected national sample of about 6,000 people age 16 or older. Interviewing began January 9, 2007, and ended April 30, 2007.

Specific questions from the survey are noted in Crash Injury and Emergency Medical Services Report (Boyle \& Lampkin, 2008). 


\section{Appendix G}

\section{GES Codes Used to Identify Distracted Driving Crashes in the Volpe Study}

Table 1 lists potential values for driver distraction as listed in the NASS GES Analytical User's Manual 1988-2003. However, in many of the following analyses the outcome being tested is dichotomous: whether distraction was involved or not. Thus, the codes from Table 1 have been reclassified into three categories, as represented in Table 2: "distracted", "not distracted", and "unknown". For all tests that involve a binary response, the category unknown is ignored.

\section{Table 1}

\section{Driver Distracted (by) Codes and Definitions}

\begin{tabular}{c|l}
\hline Code & \multicolumn{1}{|c}{ Definition } \\
\hline 0 & Not distracted \\
\hline 1 & Looked but did not see \\
\hline 3 & By other occupants \\
\hline 4 & By moving object in vehicle \\
\hline 5 & While talking or listening to phone \\
\hline 6 & While dialing phone \\
\hline 7 & While adjusting climate control \\
\hline 8 & While adjusting radio, cassette or CD \\
\hline 9 & While using other devices integral to vehicle \\
\hline 10 & While using or reaching for other devices \\
\hline 11 & Sleepy or fell asleep \\
\hline 12 & Distracted by outside person or object \\
\hline 13 & Eating or drinking \\
\hline 14 & Smoking-related \\
\hline 93 & Not on PAR \\
\hline 94 & Not coded \\
\hline 95 & No driver present \\
\hline 96 & Not reported \\
\hline 97 & Inattentive or lost in thought \\
\hline 98 & Other distraction or inattention \\
\hline 99 & Unknown if distracted \\
\hline & \\
\hline & \\
\hline
\end{tabular}

Table 2

Reclassification of Driver Distraction Codes

\begin{tabular}{l|l}
\hline \multicolumn{1}{c|}{ Reclassification } & \multicolumn{1}{|c}{ Codes (from Table 1) } \\
\hline Distracted & $1,3,4,5,6,7,8,9,10,12,13,14,97,98$ \\
\hline Not Distracted & $0,11,95$ \\
\hline Unknown & $93,94,96,99$ \\
\hline
\end{tabular}

U.S. Department of Transportation

National Highway

Traffic Safety

Administration

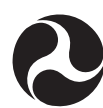

NHTSA's National Center for Statistics and Analysis
This research note and other general information on highway traffic safety may be accessed by Internet users at: www-nrd.nhtsa.dot.gov/CATS/index.aspx 